\title{
Testing the performance characteristics of specific profiles for applications in wind turbines
}

\author{
Krzysztof Pytel $^{1}{ }^{*}$, Stanislaw Gumula ${ }^{1}$, Piotr Dudek ${ }^{1}$, Sebastian Bielik ${ }^{1}$, Szymon Szpin ${ }^{1}$, \\ Wiktor Hudy ${ }^{2}$, Matgorzata Piaskowska - Silarska ${ }^{2}$, and Marcin Kowalski ${ }^{2}$ \\ ${ }^{1}$ AGH University of Science and Technology, al. Mickiewicza 30, 30-059 Krakow, Poland \\ ${ }^{2}$ Pedagogical University of Cracow, ul. Podchorazych 2, 30-084 Krakow, Poland
}

\begin{abstract}
The publication presents the results of aerodynamic characteristics of selected profile blades for applications in wind turbines. Considering the potential of energy resources and investors' preferences, the amount of energy produced in wind farms in the total amount of electricity generated will be systematically growing and probably, in the next few years, wind energy will be the first in the field of electricity production from all types of power plants. Harnessing the power of moving air masses is now a global phenomenon. Rotor wheel converts wind energy into mechanical energy when using blades with chosen shape and oriented in the terms of the optimum performance. The aim of the measurements was to determine the impact of blade shape and blade angle of attack on the efficiency of conversion of wind energy into mechanical energy on the rotor wheel. The obtained power coefficients were presented as results.
\end{abstract}

\section{Introduction}

One of the most important subjects appearing in a contemporary power engineering is examining modern technologies. Properly directed development of energy technologies enabling the use of renewable sources is very important. These technologies make it possible to obtain as much energy as possible using renewable sources. One of the most important technologies indicates the use of energy of moving air masses [1]. A wind was already used in ancient times to automate everyday tasks. The history of a wind energy shows evolution from the use of simple, light devices powered by aerodynamic drag forces to the use of a heavy, wind-intensive equipment that uses aerodynamic lift forces. The oldest known information about the windmill dates back to 3000 years ago to ancient Persia, where the windmills were used to grind grains and pump water. The external walls of the structure were used as a steering apparatus that determined the wind direction on vertical blades rotating around the central axis. Early Persian and Chinese windmills with vertical axis of rotation of a rotor were characterized by a low use of energy of moving airstream; it is estimated up to about $16 \%$. The development of technology has led to the creation of a huge variety of types and models of wind turbines with rated power from a few $\mathrm{kW}$ to several MW, from the beginning of $20^{\text {th }}$ century [2]. Savonius and Darrieus invented the most common known

\footnotetext{
* Corresponding author: kpytel@agh.edu.pl
} 
vertical axis wind turbines, and they are named Savonius and Darrieus wind turbines. Another example is the wind turbine, also known as the Giromill or H rotor; it is a kind of a vertical axis wind turbine developed by Georges Darrieus. A cycloturbine is the Giromill variant that uses vane to set the blades for maximum efficiency. In the cycloturbines, the blades could rotate around their vertical axis. This makes it possible to set the position of blades in relation to the wind.

Blades of a Darrieus' turbine are usually made as airfoil. The purpose of the work is to develop a model of a wind turbine with a vertical axis of rotation equipped with a new shape of blades. The model of wind turbine blades analysed in the wind tunnel with experimental aerodynamic parameters were scanned. The blades were modified, then numerical analyses of the blades were made, and then simulations of a rotor of the vertical axis wind turbine model were carried out. The conducted research allowed determining the sense of using the new designed profiles of blades based on the value of power coefficients. The proper selection of materials for making the device's components is another important issue to solve $[3,4]$.

\section{Description of the tested wind turbine rotor}

Wind turbines constructed today are based on many achievements of aviation technology. The production of wind turbine components has a lot in common with the aviation industry. These similarities mainly concern operating conditions, which in both cases take place at varying wind speeds and directions.

Table 1. Data for calculations.

\begin{tabular}{|c|c|c|}
\hline & new profile & DU 06-W-200 profile \\
\hline cross-section of the profile & 105 & 100 \\
\hline $\mathrm{c}-$ length of the profile chord, $\mathrm{mm}$ & 440 & 445 \\
\hline $\mathrm{H}-$ blade height, $\mathrm{mm}$ & 3 & 3 \\
\hline $\mathrm{N}_{\mathrm{b}}-$ blade number & 250 & 250 \\
\hline $\mathrm{R}_{\mathrm{z}}-$ radius of rotor, $\mathrm{mm}$ & 500 & 500 \\
\hline $\mathrm{D}-$ diameter of rotor, $\mathrm{mm}$ & $5-25$ & $5-25$ \\
\hline $\mathrm{v}-$ wind speed before rotor, $\mathrm{m} / \mathrm{s}$ & 12 & 12 \\
\hline $\mathrm{V}_{\text {rated }}-$ rated wind speed, $\mathrm{m} / \mathrm{s}$ & 5 & 5 \\
\hline $\mathrm{V}_{\min }-$ start-up wind speed, $\mathrm{m} / \mathrm{s}$ & 25 & 25 \\
\hline $\mathrm{V}_{\text {max }}-$ maximum wind speed, $\mathrm{m} / \mathrm{s}$ & & \\
\hline
\end{tabular}

Both in an aviation and in a wind power engineering, the geometry of the blade has a decisive impact on all characteristics of the wind turbine or airplane performance. The surface and profile of the airfoil are of a great importance and can cause significant differences in the performance of the power plant with the same dimensions of the blades. Even slight differences in shape can significantly change the characteristics of rotor of wind turbine [5].

The selection of the right shape of a blade is very important, because the properly selected shape of a vertical axial wind turbine blade is required to satisfy both aerodynamic and 
mechanical criteria. Increased a blade width allows to maintain performance in a larger range. Due to the thickening of the profiles, it is possible to obtain a higher strength of the structure [6].

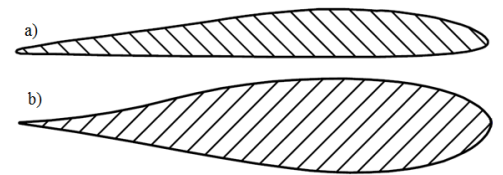

Fig. 1. Visual information about the differences in geometry between a new profile (a) and DU 06W-200 (b) airfoils.

Two types of blade profiles, shown in Figure 1, used for a construction of a rotor of a model wind turbine were analysed, shown in Table 1 . A power coefficient $c_{p}$ was used as a norm for analysis. The power coefficient is used to calculate the amount of energy possible to receive from the wind. The kinetic energy of the air mass moving at the specified speed can be expressed as the product of air velocity and mass [7]. This shows the following formula:

$$
E_{k}=\frac{m v^{2}}{2}=\frac{\rho V v^{2}}{2}=\frac{\rho v A v^{2}}{2}=\frac{\rho A v^{3}}{2}
$$

where:

$\mathrm{m}$ - is a mass of the body;

$\mathrm{v}-$ is a velocity of the body;

$\rho-$ is a density of the body;

$\mathrm{V}-$ is a volume of the body;

$\mathrm{A}-$ is a surface of the rotor wheel.

Thus, the equation expressing the kinetic energy of the moving air and mass can be represented as the amount of energy passing through the cross-section A, in time. This energy corresponds to the physical wind power. In fact, it is impossible to use the total wind power. In practice, only part of the wind power is actually used to set the turbine in motion [8]. The mechanical power of a wind turbine is calculated by reducing the wind power by the power coefficient $c_{p}$. Therefore, the power can be calculated as:

$$
E_{k}=\frac{\rho A v^{3}}{2} c_{p}
$$

where:

$\mathrm{c}_{\mathrm{p}}-$ is a dimensionless power coefficient.

The value of the power coefficient $c_{p}$ depends on the speed of moving air before and after the rotor. The velocity of the air stream entering the rotor and the air velocity after the rotor is expressed as $v_{1}$ and $v_{2}$, respectively. In the method using the Betz limit, the $c_{p}$ equation has the form:

$$
c_{p}=\frac{1}{2}\left\lfloor 1-\left(\frac{v_{2}}{v_{1}}\right)^{2}\right\rfloor\left\lfloor 1+\left(\frac{v_{2}}{v_{1}}\right)\right\rfloor
$$

The diagram of the power coefficient $c_{p}$ in relation to the air velocities described by the Betz limit shows the theoretical $c_{p}$ values, but the determined values of the $c_{p}$ are lower due to various types of losses [9]. 


\section{Numerical procedure}

The new profile was prepared based on an experiment with an economically effective zero-camber profile. The new profile was made and tested in the wind tunnel. In order to determine the operating parameters, the analysed profile was made by reverse engineering and examined in digital form. Profiles were studied in the CFD application. Autodesk Simulation CFD software was used for analysis. Application performs a comprehensive examination of the analysis geometry and fixes the mesh size. The finite element mesh has been sizing automatically. Velocity is used as an inlet boundary condition, it is specified as normal in Cartesian coordinates. A pressure is be applied to an outlet. The study was carried out at three rotational speeds, minimum, nominal and maximum, which $5 \mathrm{~m} / \mathrm{s}, 12 \mathrm{~m} / \mathrm{s}$, and $25 \mathrm{~m} / \mathrm{s}$ values were assumed, respectively. A minimum speed is the wind speed at which it is possible to start the operation of the wind turbine. A rated speed is the wind speed at which the wind turbine should obtain a nominal power. A maximum speed is the wind speed at which the wind turbine can operate safely, without exposing the rotor structure to the destructive effect of centrifugal forces, vibrations and other factors that may damage the rotor of the wind turbine [10].

During numerical simulations, airflow velocities were observed on additional planes and velocity measurements were made at the characteristic points of the profile. The velocity of the moving air shows the flow velocity distribution, shown in Table 2.

Table 2. The distribution of air speed for DU 06-W-200 and designed blade profile at different speeds of the airflow.

\begin{tabular}{|c|c|c|}
\hline & DU 06-W-200 & new profile \\
\hline $\begin{array}{c}\text { wind } \\
\text { speed } \\
\text { before } \\
\text { rotor } \\
\text { wheel } \\
\text { equal to } \\
5 \mathrm{~m} / \mathrm{s}\end{array}$ & 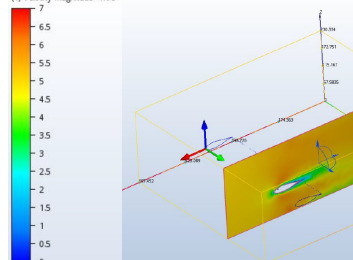 & 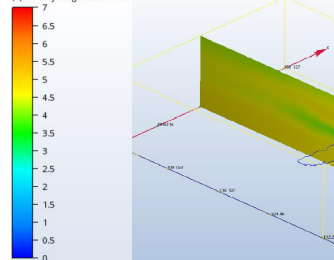 \\
\hline $\begin{array}{c}\text { wind } \\
\text { speed } \\
\text { before } \\
\text { rotor } \\
\text { wheel } \\
\text { equal to } \\
12 \mathrm{~m} / \mathrm{s}\end{array}$ & 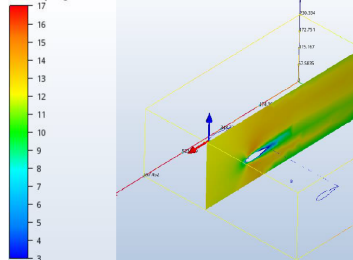 & {$\left[\begin{array}{l}-17 \\
-16 \\
-15 \\
-14 \\
-13 \\
-18 \\
-12 \\
-11 \\
-10 \\
-9 \\
=-7 \\
-6 \\
-5 \\
-5\end{array}\right.$} \\
\hline $\begin{array}{c}\text { wind } \\
\text { speed } \\
\text { before } \\
\text { rotor } \\
\text { wheel } \\
\text { equal to } \\
25 \mathrm{~m} / \mathrm{s}\end{array}$ & 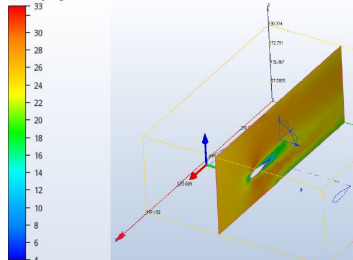 & 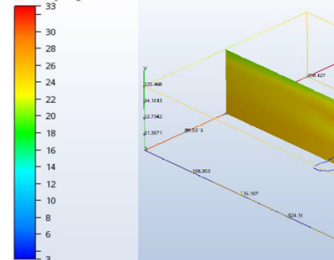 \\
\hline
\end{tabular}

Simulations were carried out for the rotor prepared from selected blades, shown in Figure 2. The speed of the moving air shows the flow velocity distribution in six measuring points, three in a free stream of air before and three directly behind the rotor wheel, shown in Figure 3. 
The visible differences, shown in Table 3, results from the change in speed and pressures. The lift and drag force acting on the rotor blades and interacts during the movement of the blades. Analyses were conducted for DU 06-W-200 and new designed blade.

Based on information about the airflow velocity collected at the measurement points before and after the rotor, the averaged value of the airflow velocity was determined.

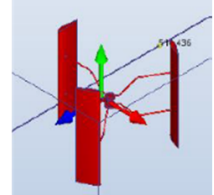

Fig. 2. Model of a rotor.

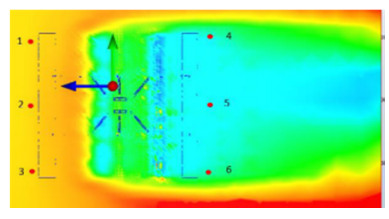

Fig. 3. Speed measuring points in front of and behind the rotor.

Based on obtained results, the value of the power coefficient $c_{p}$ was determined, shown in Figure 4. The value of the $c_{p}$ coefficient gives higher values for the designed profile for cut-in and cut-out speed. The rotor with the new blades obtained a slightly worse value of $c_{p}$ than DU 06-W-200 for rated wind speed, hence the information about necessity to improve the new designed rotor blade.

Table 3 The distribution of air speed for DU 06-W-200 and designed blade profile at different speeds of the airflow.

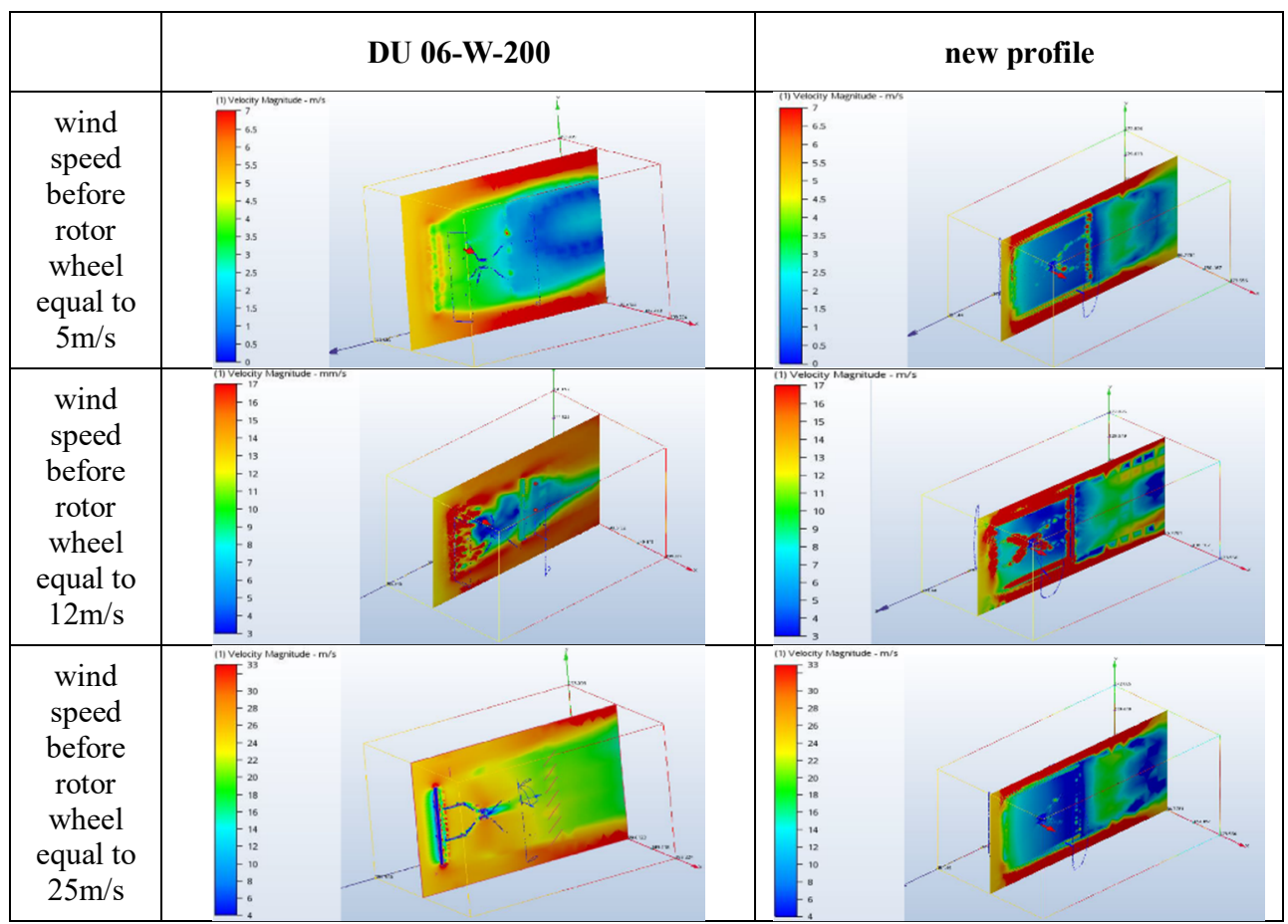

The geometry of the rotor blade has a decisive impact on the characteristics of the wind turbine. The surface and profile of the airfoil are of great importance and can cause significant differences in the performance of the power plant with the same overall dimensions of the rotor. 


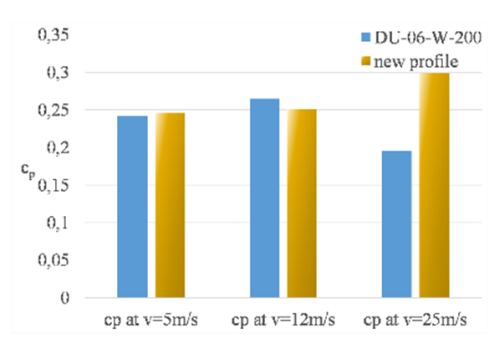

Fig. 4. Values of power coefficients at three airflow velocities.

Seemingly minor differences in shape of the rotor blade can meaningfully change the characteristics of the rotor, thus the properly profiled blades guarantee high efficiency of the wind power plant [11].

\section{Conclusion}

The wind turbine with the vertical axis of rotation is the simple construction. The ability to build small devices working independently of the direction of the wind is its main advantage. This uncomplicated construction gives many opportunities to obtain electricity in places where access to grids is limited or impossible [12-14].

One of the methods to optimize the rotor wheel is to change the shape of the rotor blade. Based on the computed in simulations power coefficients, studies in a wind tunnel can be proposed.

The wind turbines constructed today are based on the achievements of aviation technology in which aerospace profiles are used. New advanced technologies, light and durable materials and the ability to perform complex aerodynamic simulations give designers the great opportunities to project both the rotor blade and the entire wind turbines. A contemporary engineering education perfectly fits the tendency to respect renewable energy and environmental protection [15].

\section{References}

1. S. Gumula, W. Hudy, M. Piaskowska-Silarska, K. Pytel, Przemysł Chemiczny, 94 (2015)

2. A.Bianchini, G. Ferrara, L. Ferrari, Conversion and Management 89 (2015)

3. T. Prauzner, Przegląd Elektrotechniczny 88 (2012)

4. J. Suchanicz, G. Stopa, J. Kusz, M. Zubko, W. Hofmeister, M. Antonova, A. Kalvane, M. Dambekalne, A. Sternberg, I. Jankowska-Sumara, B. Garbarz-Glos, D. Wcisło, K. Konieczny, K. Pytel, A. Finder, J Mater Sci 45 (2010)

5. P. Dulian, B. Garbarz-Glos, W. Bąk, M. Antonova, C. Kajtoch, K. Wieczorek-Ciurowa, H. Noga, Ferroelectrics 497 (2016)

6. S. Gumula, K. Pytel, M. Piaskowska-Silarska, Pol. J. Environ. Stud. 23 (2014)

7. W.Hudy, K. Jaracz, K. Pytel, ICCC 16 (2015)

8. M. L. Niculescu, M. G. Cojocaru, M. V. Pricop, D. Pepelea, A. Dumitrache, D. E. Crunteanu, AIP Conference Proceedings 1863 (2017)

9. Jin Zhang, Ke Chen, Bo Yu, Applied Mathematical Modelling 40 (2016)

10. G. Ronsten, Journal of Wind Engineering and Industrial Aerodynamics 39.1 (1992) 
11. F. Spinato; P.J. Tavner; G.J.W. Van Bussel; E. Koutoulakos, IET Renewable Power Generation 3.4 (2009)

12. K. Pytel, W. Hudy, H. Noga, W. Kulinowski, ICCC 17 (2016)

13. F.D. Bianchi, H. de Battista, R.J. Hernán, Wind Turbine Control Systems. Principles, Modelling and Gain Scheduling Design ( Springer, 2007)

14. S. Gumula, W. Hudy, M. Piaskowska-Silarska, K. Pytel, Archives of Mining Sciences 62 (2017)

15. D. Olszewska, T. Prauzner, P. Ptak, H. Noga, Przegląd Elektrotechniczny 12 (2016) 